\title{
A ESCOLA FRENTE AO FENÔMENO DOS JOGOS ELETRÔNICOS: ASPECTOS MORAIS E ÉTICOS
}

\author{
Daniela Karine Ramos - Universidade Federal de Santa Catarina - \\ dadaniela@gmail.com
}

\section{Resumo}

Este artigo tem como objetivo problematizar os jogos eletrônicos e suas relações entre os aspectos morais e éticos de nossa sociedade, procurando identificar as ressonâncias que esse mundo virtual tem sobre a vida real. Para tanto, são apresentadas as concepções sobre os jogos eletrônicos, a moral e a ética. Além disso, pontuamos algumas pesquisas já desenvolvidas e abordamos o papel da escola. Partimos do entendimento que o mundo virtual dos games contribui para criar um imaginário ficcional abrangente, que oferece outra forma para entender o real e agir sobre ele. Por fim, a escola precisa se apropriar do universo dos jogos eletrônicos para criar espaços de discussão e problematização, reforçando a diferenciação entre o mundo virtual e o real, contribuindo para que os jogos consolidem-se como um espaço de aprendizagem, ficção e fantasia.

Palavras-chave: jogos eletrônicos; educação; moral; ética.

\section{THE SCHOOL FACING THE PHENOMENON OF ELETRONIC GAMES: MORAL AND ETHICAL ASPECTS}

\begin{abstract}
The aim of this article is to analyze the problem of electronic games and its relations with moral and ethical aspects in our society, to identify the resonances that this virtual world has on the real life. For that, the conceptions of electronic games, of moral and of ethic are presented. Moreover, we show some researches already developed and we approach the role of school in this process. Our premise is that the virtual world of games contributes to create an imaginary world, that offers another way of understanding the real world and to act on it. Finally, school needs to appropriate itself of the universe of electronic games to create spaces of quarrel and reflection, strengthening the differentiation between the virtual world and the real world, in such a way that the games became a space of learning, fiction and fantasy

Keywords: electronic games; education; moral; ethic.
\end{abstract}

\section{Introdução}

Diante do contexto em que vivemos e do papel fundamental que a técnica exerce sobre a nossa vida, podemos entender os jogos como mais uma das técnicas criadas pelo homem.

A própria concepção de jogo tem evoluído e, atualmente, estamos diante de uma nova categoria que incorpora os recursos tecnológicos computacionais e eletrônicos para trabalhar aspectos lúdicos, imaginários, ficcionais e imersivos, que são os jogos eletrônicos ou games. 
Este tipo de jogo volta-se para um público habilidoso na manipulação dos recursos das tecnologias da comunicação e informação. Para Rushkoff (1999), esta geração é denominada screenagers e interage muito bem com os controles remotos, joysticks, mouse, Internet, bem como pensa e aprende de forma diferenciada e descontínua.

Os jogos, direcionados a essa geração, oferecem possibilidades de aprendizagem que são descontínuas e atraentes, utilizando mecanismos e recursos. Segundo Costa (2002) o desenvolvimento desses contribui para criar um imaginário ficcional abrangente, que oferece outra forma para entender o real e agir sobre ele.

Nesse sentido, compreender essa outra forma passa a ser um grande desafio aos pesquisadores. Do mesmo modo, estamos diante de outra forma de jogar com o desenvolvimento da técnica que influi em nossos modos de vida e em nossos aspectos afetivos e cognitivos.

A partir disso, nesse artigo apresentamos a concepção de jogos eletrônicos, propomos alguns relações entre esses espaços virtuais e aspectos morais e éticos e pontuamos o papel da escola diante das questões levantadas.

\section{Jogos eletrônicos: conceitos}

Podemos entender os jogos eletrônicos dentro de uma categoria mais ampla que é o jogo. Assim, muitas características que encontramos no jogo "tradicional" estão presentes no jogo eletrônico, bem como há outras que se diferenciam e caracterizam este tipo de jogo, revelando, então, suas especificidades.

A característica comum a essas diferentes modalidades de jogos é que eles são recreativos, ou seja, "não oferecem nenhum benefício imediato para nossa sobrevivência" (Murray, 2003, p. 142). Entretanto, mesmo recreativos "oferecem treinamento seguro em áreas que possuem um valor prático real; eles constituem ensaios para a vida" (Idem).

Por outro lado, os jogos eletrônicos combinam diferentes linguagens, o ambiente virtual e multimídia, que combina imagens, sons e textos (Kruger e Cruz, 2001). E incluem os mini-games, os jogos para computador (em rede ou não), os softwares para videogames, os simuladores e os fliperamas e se constituem como artefatos de grande fascínio econômico, tecnológico e social. Esse fascínio é evidenciado pelo grande consumo e pelo crescimento da indústria de jogos eletrônicos (Mendes, 2006).

No que ser refere às categorias dos jogos e sua relação com os contextos escolares, Mendes (2006, p. 79) identifica três categorias de jogos, observando seus interesses, objetivos, conteúdos e avaliações empregadas:

1. Jogos comerciais - são produzidos para serem vendidos a um maior número de consumidores e têm objetivos educativos, porém não de uma pedagogia escolar. São exemplos: 007 Nighfire, Final Fantasy e $O$ Senhor dos Anéis: $O$ retorno do rei.

2. Jogos educativos - possuem uma grande variedade, são direcionados a um público específico, procuram cumprir objetivos de ensino, aproximando-se do currículo escolar. São exemplos: Conta outra vez?, Jogos das letras, Jogos da forca.

3. Jogos eletrônicos como ferramentas educacionais - quando empregados em ambientes educacionais formais, podem ser mais um instrumento de ensino. São exemplos: a série Civilization e Sim City. 
Cabe ressaltar que independente da categoria do jogo, de acordo com Greenfield (1988), todos combinam o dinamismo visual com a possibilidade de participação ativa e essa última característica é o que torna esse meio tão atraente.

Johnson (2005) nos chama a atenção para a forma como os jogadores interagem com os jogos, os desafios e as tarefas propostas por eles. Em alguns jogos é possível identificar tarefas repetitivas para alcançar-se um objetivo do jogo. Além disso, há dificuldades impostas que fazem o jogador sentir-se perdido e sem saída, o que justifica a compra de revistas especializadas, a consulta a sites e a interação em comunidades para alcançar as metas definidas pelos jogos. Diante disso, nos cabe questionar até que ponto ou como isso pode ser divertido e prazeroso.

Do mesmo modo, evidencia-se a necessidade de superação, a partir do esforço e empenho individual ou coletivo para concluir um jogo, perpassado por sentimentos competitivos e de auto-afirmação de sua qualidade como jogador.

Nesse sentido, Greenfield (1988) denomina de escalada de desafios a possibilidade oferecida pelos jogos eletrônicos de avançar nas suas fases e experimentar novos desafios que tendem a uma maior complexidade. Segundo a autora "a existência de múltiplos níveis proporciona maior variedade ao jogo e cria curiosidade sobre como será o próximo nível” (1988, p. 104). Segundo essa mesma autora (1988, p. 105) esses desafios envolvem "situações sempre novas de jogo, acrescidas ao sentimento de controle que as crianças dizem que o computador lhes proporciona, cria um atrativo duradouro".

Outra característica importante dos jogos eletrônicos diz respeito à interatividade, ou seja, a "possibilidade do usuário participar ativamente, interferindo no processo com ações, reações, intervenções, tornando-se receptor e emissor de mensagens que ganham plasticidade, permitem a transformação imediata (Alves, 2004, p. 47)", também relacionadas às possibilidades tecnológicas digitais.

Desse modo permite criar "novos caminhos, trilhas, cartografias, valendo-se do desejo do sujeito" (Idem). Acrescenta-se também a capacidade que esses novos sistemas têm para "acolher as necessidades do usuário e satisfazê-lo" (Battetini apud Alves, 2004, p. 67).

A partir das características e possibilidades descritas podemos perceber o potencial de atrair crianças e jovens para vivência de experiências virtuais. Essa fato acaba por "prender" esses sujeitos por muito tempo em atividades relacionadas aos jogos eletrônicos, o que gera preocupações de pais, pesquisadores, professores e outras autoridades com relação à influência que esses meio exercem sobre o desenvolvimento humano em seu aspecto mais amplo, que inclui o desenvolvimento moral e a formação ética.

\section{Aspectos morais e éticos relacionados aos jogos eletrônicos}

O processo de construção da moral, das regras e valores sociais pode ser compreendido levando em conta tanto aspectos da evolução humana, como aspectos sociais e filosóficos.

No que diz respeito aos aspectos sociais, cabe ressaltar que as regras e os valores sociais, já estão previamente construídos quando a criança entra no mundo no social. Além disso, é sabido que os aspectos morais e os valores de uma sociedade modificamse com o tempo e podem variar de acordo com a cultura. 
Por outro lado, os aspectos da evolução humana resgatam elementos do processo evolutivo que envolve não só aspectos biológicos, como também questões sociais, nas quais estão envolvidas a moral, a ética e os valores, que orientam o homem em sua trajetória de transcendência, para além de seus impulsos. Essa superação segundo Alberoni (2000, p 14) ocorre por meio da "lenta evolução dos costumes, que impõe tabus, limites e vínculos à sofreguidão do instinto".

No campo de estudo da moral, seja sob o ponto de vista da psicologia ou filosófico, podemos identificar uma grande diversidade epistemológica e, consequentemente, diferentes métodos de pesquisa.

A partir disso, em nosso trabalho partimos do entendimento da moral como a relação entre o bem e o mal, o certo e o errado, definido dentro de um contexto social e cultural, introjetado no sujeito a partir dos processos educacionais. E a ética transcendendo a moral, incluindo o sujeito e as suas vivências, enquanto um processo autônomo e que orienta o modo de existência dos sujeitos, incluindo princípios universais e a consciência.

Assim, ser ético supõe a capacidade de avaliar as situações, colocar-se no lugar do outro, o respeito mútuo, bem como os princípios de justiça, por não ser regido; considera o contexto e razões, exigindo uma postura ativa e consciente do sujeito.

A possibilidade de colocar-se no lugar do outro, descentralizar o ponto de vista, contribui para a efetividade do julgamento moral, pois permite refletir criticamente, levando em conta os diferentes pontos de vistas e considerando os motivos, emoções e condições para determinados comportamentos.

Nessa perspectiva os jogos eletrônicos permitem que o jogador vivencie diferentes papéis, ora ele pode assumir o papel do bandido, ora do policial ou do médico, o que facilita o colocar-se no lugar do outro, pois se vive o outro no jogo e assume-se as suas funções, o que permite relativizar e refletir sobre os diferentes papéis assumidos. Essa reflexão é possível quando se encontra espaço e interlocutores para tal. A partir disso, essa atividade pode constituir-se como um exercício para a descentralização de um ponto de vista, favorecendo o desenvolvimento da empatia e da flexibilização do olhar sobre um fenômeno.

Outro aspecto importante relacionado as vivências no mundo dos jogos eletrônicos é trazido por Jones (2004) que interagiu e pesquisou jovens jogadores, a partir disso relata o caso de Richard um jovem que ao jogar Quake exercita sua fantasia de poder, mas o poder de manter-se calmo em uma realidade assustadora. Assim, ao sair da fantasia do jogo, podia voltar a sua realidade difícil, sentindo-se renovado para a batalha.

Esse jovem queria que os garotos raivosos e assustados do seu centro juvenil tivessem o mesmo mundo de fantasia no qual pudessem matar seus próprios monstros. Não nos tornando pessoas melhores devido o medo e às preocupações, mas tornandonos pessoas melhores por meio de coragem, confiança e calma. Quanto mais formos capazes de enfrentar a violência e o sofrimento com coragem e de maneira realista, mais eficiente seremos contra eles (Jones, 2004, p. 123).

Por outro lado, é comum ouvirmos noticiários que narram atos de violência e que de alguma forma os relacionam aos jogos de violência, como o ocorrido na escola de Columbine, nos Estados Unidos. De acordo com Jones (2004) é compreensível que ao se descobrir que os garotos responsáveis pelo ataque aos colegas jogavam muitos games de atirar, chegue-se a conclusão de que esses jogos influenciaram a se transformar em assassinos. 
A partir disso, podemos até mesmo encontrar suposições que sugerem que os valores morais, do que é certo ou errado, foram alterados e deturpados. Assim, a interação com os jogos de atirar contribuiu para alterar a percepção dos jovens sobre o que é certo no mundo real, passando a autorizar seus instintos mais primitivos de violência e auto-afirmação de sua força física pelo uso de uma arma de fogo. Tecnologia essa que amplia as potencialidades de força física humana, facilitando o ataque e a execução de pessoas.

Porém, se levássemos essa hipótese e inferência de modo tão simplificado, certamente, teríamos um número muito superior de jovens assassinos e violentos na sociedade moderna. A análise de fatos como esse é complexa e perpassa inúmeras instâncias de formação e desenvolvimento da personalidade de um indivíduo.

De acordo com os dados colhidos pelo Dr. James McGee, segundo Jones (2004), relata que dos dezesseis tiroteios motivados por raiva em escolas americanas, protagonizados por dezoito adolescentes nos últimos anos, incluindo o de Columbine. Apenas neste último, os jovens foram identificados como jogadores exagerados de games. Os outros jovens demonstraram gostar de games em diferentes graus, sendo que alguns não tinham nenhum interesse em videogames. De fato o que os singulariza é o fato de ter interesse em atirar com armas de verdade. Outros elementos comuns identificados entre esses jovens são: "costumavam ser ameaçados pelos colegas, eram hostis e isolados dos pais, tinham feito ameaças de suicídio em mostravam fascinação por notícias a respeito de tiroteios anteriores" (Jones, 2004, p. 187).

Antes de qualquer coisa, é preciso conhecer os games e o papel que a violência e as cenas sangrentas representam para o jogador. E ao estudar a relação que os jovens estabelecem com os games é preciso ouvi-los e fugir de inferências simplistas.

De acordo com Jones (2004), estudos mostram que se um jogador tiver que escolher entre um jogo sangrento que não desafia e um sem violência que o desafia, geralmente vai preferir a segunda opção, pois os jovens preferem o desafio ao sangue. Isso se justifica ao considerar-se que a forma de jogar é o elemento mais importante e envolve a dificuldade, as estratégias, a complexidade e em seguida vêm o ambiente e a aparência do mundo virtual.

Esse mundo virtual "possui uma realidade intensiva (quantidade intensiva abstrata) dotada de uma potência de singularização por pontos relevantes" (Alliez, 1996, p. 20). O atual é definido pelo presente que passa, mas é no virtual que o passo se conserva.

Desse modo, esse espaço baseia-se em aspectos da realidade para que o sujeito possa identificar-se e sentir personagem ativo, os quais são elementos de sedução. Assim, podemos entender que realidade virtual constitui-se como uma réplica simbólica do mundo real (Bret, 1997).

Além disso, este tipo de jogo que explora os recursos digitais possibilita a reprodução do real utilizando cores, imagens e movimentos e muitas vezes, segundo Mrech (1997), nos informam sobre o mundo, o refaz, transformando-o num espetáculo que permite recriar (interagir) com parte desta realidade virtual.

Além disso, as relações estabelecidas entre os sujeitos-jogadores e os jogos eletrônicos são singulares e diferentes para cada sujeito. Desse modo, apresentamos aqui algumas possibilidades de relação, mas que não podem ser generalizadas. Tendo em vista que também podemos identificar um endereçamento que inclui sujeitos com algumas características específicas, como habilidades técnicas, acesso a cultura digital ou domínio e familiaridade com os recursos de comunicação mediada. Além disso, há 
uma distância entre aquilo que é veiculado nos jogos e como isso toca e se inscreve no sujeito.

A partir disso, podemos supor que do mesmo que a literatura traz uma ficção, as narrativas produzidas/construídas na virtualidade também. E assim como a crise pode gerar a necessidade da escrita, os jogos eletrônicos podem configurar-se como uma possibilidade de fuga da realidade para alguns sujeitos, valendo-se da ficção.

A ficção para Costa (2002, p. 12) é uma "forma peculiar da comunicação humana que, estimulando a imaginação e o devaneio, propõe uma experiência intersubjetiva na qual a realidade circunda se apresenta de forma indireta"

Nesse sentido, o sujeito se coloca em situações ficcionais dentre as quais os valores morais são relativizados e permissivos, tendo a em vista a distinção entre o real e o virtual.

Espinosa (apud Deleuze, 2002, p. 28) ao questionar esses valores, propõe que "não existe o Bem ou o Mal, mas o bom e o mau", pois "bom e mau têm um primeiro sentido, objetivo, mas relativo e parcial: o que convém à nossa natureza e o que não convém" (p. 29). Segundo ele, "todos os fenômenos que agrupamos na categoria do Mal, doenças, morte, são deste tipo: mau-encontro, indigestão, envenenamento, intoxicação, decomposição de relação" (Idem). Entretanto esses valores morais sociais são aplicados ao mundo real que vivemos e a sociedade que convivemos, entretanto nos mundos virtuais essa moral construída e introjetada, muitas vezes, contrária aos nossos desejos, fica suspensa, por exemplo, quando estamos jogando e quando participamos de um mundo virtual. Ou mesmo é possível que esse mundo também tenha sua própria moral, definida a partir das regras de jogo e possibilidades de comportamento dos personagens.

Tendo em vista que esses valores morais são desenvolvidos e introjetadas no homem, como forma de controle e domesticação para a vida em sociedade. Segundo Nietzsche (1998, p. 73) esses fizeram com que os instintos se voltassem para dentro, contra si mesmo, assim todo o "mundo interior, originalmente delgado, como que entre duas membranas, foi se expandindo e se estendendo, adquirindo profundidade, largura e altura, na medida em que o homem foi inibido em sua descarga para fora". Assim, os jogos podem revelar-se espaços para a descarga do que é inibido.

A partir disso, podemos discutir os jogos sobre a luz da ética enquanto linha traçada para contenção, traça uma borda e o separa o que é impossível ou proibido de ser realizado. Essa contenção gera uma pressão que precisa ter vazão, a qual pode acontecer nos espaços virtuais, pois nesse a ética e moral ficam suspensas, criando um ambiente de maior autonomia e liberdade.

Desse modo podemos evidenciar uma nova roupagem do princípio do sacrifício que é o princípio da exclusão, mas já não como nas sociedades primitivas, nas quais era excluído do convívio social o que não se podia tocar. No mundo contemporâneo excluise para o mundo virtual, no qual podemos ser diferentes, ser agressivos, belos, assassinos ou donos de impérios.

Assim, o jogo possibilita um gozo consigo mesmo, pois se cria um personagem para consumo de si. Constituindo-se como um deslocamento enquanto "meio mais adequado do inconsciente para despistar a censura” (Lacan, 1998, p. 515).

\section{Os jogos eletrônicos nos contextos escolares}


Atualmente, começamos a reconhecer o potencial educativo que o jogo eletrônico possui, pois ele afirma uma "predisposição para se aprender, pois cria situações de desafio, ao mesmo tempo em que liberta, enquanto normatiza, organiza e integra" (Moita, 2007, p. 18).

De outro modo, quando pensamos no uso dos jogos eletrônicos como recurso pedagógico e nos reflexos destes sobre o desenvolvimento humano, o professor passa a ter uma função estratégica. Tendo em vista que precisa incorporar este tipo de jogo em sua prática para promover a aprendizagem, bem como conhecer e lidar com a nova geração que chega à sala de aula, querendo um espaço rico em estímulos com o qual possa interagir e desenvolver sua autonomia.

Os jogos são mídias que produzem imagens, despertam afetividades, utilizam técnicas de persuasão que invadem o cotidiano e criam uma nova realidade "mais interessante, segura e previsível" do que a nossa realidade conturbada (Costa, 2002, p. $65)$.

Além disso, os jogos eletrônicos são tidos como modos de subjetivação que, de acordo com Mendes (2006, p. 48), envolvem técnicas intelectuais - "ler, contar, memorizar, anotar, registrar, diferenciar e identificar".

Do mesmo modo, Moita (2007, p.18), nos chama a atenção para o fato de que o jogo eletrônico não só despertar o interesse das pessoas, como "oferece condições de observação, associação, escolha, julgamento, emissão de impressões, classificação, estabelecimento de relações, autonomia".

No que diz respeito à influência dos jogos e das mídias em geral sobre o desenvolvimento cognitivo, Johnson (2005) relata que o aproveitamento nos testes de QI, que foram sendo modificados para incluir a avaliação do pensamento abstrato, identificação de padrões, como o teste de Matrizes Progressivas de Raven, tem aumentado o nível do escore obtido de modo geral nesses testes. Assim, devido às modificações ocorridas no teste e o tipo de inteligência medido, esse pesquisador associa tal fato à interação com as mídias, televisão, internet e jogos eletrônicos, tendo em vista que eles desenvolvem habilidades cognitivas.

Pesquisas como a desenvolvida na Universidade de Rochester, com o objetivo de avaliar o efeito de jogar videogames na inteligência e memória visual, por meio da aplicação de testes rápidos de reconhecimento visual, demonstrou que as pessoas que jogavam regularmente tiveram melhor desempenho (Johnson, 2005).

Nesse sentido, podemos afirmar que os jogos eletrônicos proporcionam uma "alfabetização com domínios semióticos: imagens, símbolos, gráficos, diagramas e muitos outros símbolos visuais significantes" (Gee, 2004 apud Moita, 2007, p. 59).

Assim, precisamos considerar que os jogos eletrônicos fazem parte do meio no qual o sujeito se desenvolve e aprende e se consideramos o processo de aprendizagem sob uma perspectiva interacionista, precisamos considerar não só os aspectos da maturação biológica e da genética, mas o ambiente social e cultural, atualmente permeado por recursos tecnológicos atrativos e complexos que impõem desafios ao homem, gerando desequilíbrios e a necessidade de adaptação, e, assim, a aprendizagem.

Esse aspecto revela a necessidade que as escolas têm de incorporar essa lógica e esses recursos nos processos de ensinar e aprender, visando dar conta de todo universo presente, no qual ela está inserida, e também para lidar com esses alunos que não são os mesmos de anos atrás. 
Além disso, temáticas presentes em nossa sociedade também são vivenciadas nos jogos eletrônicos. Dentre essas destacamos violência e comportamentos amorais, como matar, atropelar, roubar, seqüestrar entre outros.

A proibição desses jogos não é suficiente para frear sua disseminação e conter o desejo e a atração de crianças e jovens por este tipo de jogos. Cabe a discussão sobre essas temáticas e diferenciação entre o real e o virtual.

Assim, a escola precisa trazer a tona discussão dessas culturas juvenis e tecnologias de entretenimento difundidas em nossa sociedade contemporânea, criando espaços de escuta para a socialização, discussão e crítica desses recursos, a partir da participação, exposição e problematização das próprias crianças e jovens.

De outro modo, precisamos reconhecer os benefícios que os jogos eletrônicos oferecem ao desenvolvimento cognitivo. Os jogos possuem regras pré-estabelecidas e comandos que precisam ser de conhecimento do jogador para que o mesmo tenha um bom desempenho. Isso requer um grande exercício do jogador para decorar os códigos, teclas relacionadas às ações do personagem e de controle (Mendes, 2006, p. 63).

Assim, dois desafios são gerados aos professores: primeiro lidar com esta nova geração, buscando criar estratégias e utilizar recursos que incentivem e desperte o aluno para aprender, e segundo utilizar estes recursos, como jogos eletrônicos, para promover a aprendizagem na escola, tanto de conteúdos escolares, como de valores e princípios éticos.

Nesse sentido, é preciso que os professores se aproximem e conheçam o mundo dos jogos eletrônicos, pois ele faz parte do cotidiano de muitas crianças e adolescentes. É preciso aproximar o mundo escolar do mundo cotidiano da criança, fazer relações e aproveitar potenciais dados por esses meios.

Além disso, é importante ter clareza de que os adultos têm a função de ajudar crianças e jovens a integrarem suas fantasia à vida real, estabelecendo comunicação com eles sobre os jogos eletrônicos e respeitando a sua paixão. Isso pode ser feito em sala de aula, em espaço públicos para jogar ou em casa, pois isso ajuda os jogadores a interagir de forma mais significativa com os jogos e com a sociedade (Jones, 2004).

Entretanto a inserção dos jogos eletrônicos na educação deve ser fundamentada sob uma perspectiva crítica. Segundo Mendes (2006), os jogos eletrônicos não são inocentes e educam de alguma forma, seja para o consumo e violência ou para os papéis de gênero, o que reforça o papel pedagógico também deste tipo de jogo. Questões estas que podem ser trabalhados a partir do uso dos jogos.

Além disso, os jogos estão envoltos em rumores similares aos ocasionados pelo advento do cinema e da televisão. Esses meios provocaram rumores e medos relacionados à substituição dos meios impressos, bem como mais recentemente foram cogitados como dessensibilizadores da violência, ou seja, tornavam o sujeito imparcial à cena de violência, devido à freqüência pela qual o sujeito é bombardeado por imagens de violência. Esses mesmos medos são sentidos contra o videogame que, segundo Murray (2003) adicionaram a "interatividade aos encantamentos sensoriais da visão, do som e do movimento. Críticos condenam a estimulação fácil dos jogos eletrônicos como uma ameaça aos prazeres mais reflexivos da cultura impressa".

Assim, identificamos resistências por parte dos profissionais da área da educação para introdução dos jogos como atividades escolares, muitas vezes porque as representações desse objeto social relacionam-se com violência, perda de tempo, ociosidade, entre outras. Além disso, o uso e o conhecimento desses jogos requerem 
habilidades técnicas e posturas, como não hierarquia nas relações escolares, que dificultam sua introdução.

Por outro lado, a partir do resgate de pesquisas feito por Moita (2007) realizadas por Greenfield (1988), Yuji (1996) e Gros (1998), evidenciamos as contribuições que a interação com os jogos eletrônicos oferecem ao desenvolvimento de habilidades como observação sistemática, pois em alguns jogos é preciso perceber as regras; atenção e concentração necessária para a discriminação visual; competências perceptivas e motoras e aptidões para o processamento de informação. Sendo assim, não podemos deixar de aproveitar o potencial educativo oferecido por esses jogos.

\section{Considerações finais}

Diante deste mundo virtual de jogos eletrônicos, emergem muitas questões que precisam ser melhor investigadas e permitem levantar hipóteses para serem estudadas nas escolas, visando identificar quem é esse aluno imerso na cibercultura e se ele experimenta novas formas de pensar, de aprender e de socialização.

Observamos que quando se fala dos efeitos nocivos dos jogos eletrônicos violentos não se considera a necessidade de direcionamento e limites que um sujeito precisa para se desenvolver, considera-se apenas o papel da fantasia. As crianças precisam de limites, de alguém que lhes diga até que ponto pode-se ir, por quantas horas pode-se jogar. Talvez a falta de limites estabelecidos pelos pais seja o grande problema, que pode tanto estar relacionado ao tempo que a criança fica em frente ao computador, como ao tipo de alimentação que têm.

Sabemos que hoje a presença dos pais é menor que há algumas décadas atrás e que a educação está muito mais fragilizada. Isso é facilmente identificado nas escolas, aonde professores lidam com crianças e adolescentes sem limites e desrespeitosos, como um reflexo das facilidades para realização de seus desejos e o evitamento da frustração, necessária para que o ser humano conheça seus limites e aprenda a lidar com eles.

Assim, a escola enquanto instituição que cada vez mais tem partilhado o processo educacional das crianças com a família, precisa problematizar os jogos eletrônicos, discutindo com as crianças e os jovens o que é certo e errado nesse mundo virtual, reforçando a diferenciação entre o mundo virtual e o real contribuindo para que os jogos consolidem-se como um espaço de aprendizagem, ficção e fantasia.

\section{Referências Bibliográficas}

ALBERONI, Francesco. Valores: o bem, o mal, a natureza, a cultura, a vida. Rio de Janeiro: Rocco, 2000.

ALLIEZ, Eric. Deleuze filosofia virtual. São Paulo, Ed. 34, 1996.

ALVES, Lynn Game over: jogos eletrônicos e violência, no Estado da Bahia. Salvador: PPGE/UFBA, 2004. Tese de Doutorado.

BRET, Michel. O tempo reencontrado. In: DOMINGUES, Diana. A arte no século XXI: a humanização das tecnologias. São Paulo: Fundação Editora da UNESP, 1997. COSTA, Maria C. C. Ficção, comunicação e mídias. São Paulo: Editora do SENAC São Paulo, 2002.

DELEUZE, Gilles. Sobre a diferença da Ética em relação a uma Moral. In: DELEUZE, Gilles. Espinosa: filosofia prática. São Paulo: Escuta, 2002. 
GREENFIELD, Patrícia. O desenvolvimento do raciocínio na era eletrônica: os efeitos da TV, computadores e videogames. São Paulo: Summus, 1988.

JOHNSON, Steven. Surpreendente!: a televisão e o videogame nos tornam mais inteligentes. Rio de Janeiro: Elsevier, 2005.

JONES, Gerard. Brincando de matar monstros: por que as crianças precisam de fantasia, videogame e violência de faz-de-conta. São Paulo: Conrad Editora do Brasil, 2004.

KRÜGER, Fernando L. CRUZ, Dulce M. Os jogos eletrônicos de simulação e a criança. In: Congresso Brasileiro da Comunicação, 24, 2001. Anais .... Campo Grande:

Intercom 2001. P. 1 -16.

MENDES, Cláudio L. Jogos eletrônicos: diversão, poder e subjetivação. Campinas: Papirus, 2006.

MOITA, Filomena. Game on: jogos eletrônicos na escola e na vida da geração @ . Campinas: SP: Editora Alínea, 2007.

MURRAY, Janet H. Hamlet no holodeck: o futuro da narrativa no ciberespaço. São Paulo: Itaú Cultural: Unesp, 2003.

NIETZSCHE, Friedrich. Genealogia da moral: uma polêmica.São Paulo: Cia das Letras, 1998.

RUSHKOFF, Douglas. Um jogo chamado futuro: como a cultura dos garotos pode nos ensinar a sobreviver na era do caos. Rio de Janeiro: Revan, 1999. 